\title{
MICROWAVE-ASSISTED SYNTHESIS AND PKA DETERMINATION OF UMBELLIFERONE: AN EXPERIMENT FOR THE UNDERGRADUATE ORGANIC CHEMISTRY LABORATORY
}

\author{
Thiago M. Pereira ${ }^{a}$, Daiana F. P. Franco ${ }^{a}$, Felipe Vitório ${ }^{a}$, Ronaldo C. Amaral ${ }^{\mathrm{b}}$, Aparecida C. Ponzoni ${ }^{\mathrm{a}}$ and Arthur E. \\ Kümmerle ${ }^{\mathrm{a}, *}$ \\ aDepartamento de Química, Universidade Federal Rural do Rio de Janeiro, 23897-000 Seropédica, Rio de Janeiro - RJ, Brasil \\ 'Instituto Federal de Educação, Ciência e Tecnologia de São Paulo, Campus Sorocaba, 18095-410 Sorocaba - SP, Brasil
}

Recebido em 28/03/2018; aceito em 18/06/2018; publicado na web em 23/07/2018

\begin{abstract}
A synthetic procedure for obtaining the fluorescent coumarin umbelliferone (7-hydroxycoumarin) and its spectral parameters were fully developed aiming at an undergraduate organic chemistry laboratory class. Umbelliferone is traditionally prepared via Pechmann condensation using malic acid, resorcinol and sulfuric acid as catalyst. The use of domestic microwave oven and the absence of solvent allow our methodology to be simple, fast and easy applied in obtaining umbelliferone at organic chemistry laboratory being greener than classical techniques of synthesis. In this class the student will learn how to measure the potency of a microwave oven, the applicability of this kind of irradiation in the organic synthesis of fluorescent compounds and how to determine the pKa of an organic compound through an UV/VIS spectrometric analysis. These experiments were designed to be suitable for a second and third year undergraduate curriculum.
\end{abstract}

Keywords: umbelliferone; microwave; synthesis; undergraduate; pKa.

\section{INTRODUCTION}

Microwave-assisted organic synthesis (MAOS) has attracted attention in recent years and it is increasingly present in synthetic laboratories. ${ }^{1}$ The importance of this technique of synthesis comes from its influence in drug discovery ${ }^{2,3}$ and the growth of use in industrial processes. ${ }^{3}$

The use of microwave oven in organic synthesis has demonstrated benefits compared to conventional heating, due to selective heating and dependence of only the nature of the matter. ${ }^{4}$ Moreover, the reduction in reaction times, higher chemical yields and the possibility of eliminating solvents, get interesting the introduction of this emerging technology to undergraduate students. ${ }^{5}$

Instead of classical heating techniques, when reactions are heating by conductance using an external source (e.g. oil bath), microwave heating occurs through two principal mechanisms, dipolar polarization and ionic conduction. The microwaves provide efficient internal heating by the interaction of the electric dipoles of polar molecules, with the electromagnetic field applied. When the electromagnetic field is removed, the molecules back to original state, releasing energy as heat which is absorbed during the alignment of the molecules. ${ }^{3-6}$

Domestic microwave ovens applied in synthetic organic protocols normally present low control over reaction conditions, which can lead to risks of incidents due to overheating and projection. To avoid this problem a considerable number of interesting organic synthesis has been made without solvent. ${ }^{6} \mathrm{~A}$ wide variety of papers and review articles describe the advantages of using microwave assisted organic synthesis: the possibility of higher yields, less thermal decomposition and higher heating rate in contrast to classical heating. ${ }^{7,8}$

Organic reactions have a large importance in the undergraduate curriculum due to the wide variety of applications in industrial processes. ${ }^{3,6}$ In this context, synthesis of coumarin rings (1) (Figure 1) gets great attention due to their diversified applications, such as optical brightener, fluorescent sensor, polarity probe, anticoagulant,

*e-mail: akummerle@hotmail.com
anti-HIV, antioxidant, anti-inflammatory, antifungal, antitumor and antibiotic. ${ }^{9-11}$ Umbelliferone (2) (Figure 1) is a well-known fluorescent 7-OH-coumarin found in plants, with high fluorescence quantum yields, ${ }^{12}$ antioxidant properties and has been used in sunscreen lotions. ${ }^{13}$ In addition, the umbelliferone has interesting photophysical properties ascribed to intramolecular charge transfer (ICT) states, associated the intense $\pi \rightarrow \pi^{*}$ transitions and presence of hydrogen acid, can also be properly exploited, for example, in a $\mathrm{pH}$ indicator and fluorescent sensor. ${ }^{14}$

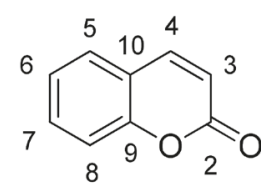

1<smiles>O=c1ccc2ccc(O)cc2o1</smiles>

2
Figure 1. Chromenone ring (coumarin) 1 and 7-OH-coumarin (umbelliferone) 2

Traditionally, the synthesis of umbelliferone (2) is performed through Pechmann condensation, ${ }^{15}$ using resorcinol, malic acid, and acid (sulfuric ${ }^{16}$ or perchloric acid ${ }^{17}$ ) as catalyst and solvent (ethanol) ${ }^{17}$ at high temperatures $\left(90^{\circ} \mathrm{C}-120^{\circ} \mathrm{C}\right)$ for approximately 2-4 hours. However, new methodologies using synthetic microwave without any solvent have been developed for the Pechmann condensation, ${ }^{18}$ and recently, Symeonidis and co-workers synthesized a set of coumarin derivatives using a synthetic microwave oven in good yields in most of the cases. ${ }^{19}$

The organic chemistry laboratory class described herein explores the optimization of the microwave synthesis of umbelliferone (2), a fluorescent molecule, using a domestic microwave oven, and its pKa value determination. Many organic chemistry concepts are covered, including Pechmann condensation, conjugation and acidbase properties, likewise important analytical techniques such as TLC, UV-Vis, fluorescence and NMR spectroscopy. The approach given to each organic chemistry concept or analytical technique is determined by the instructor according to the needs of the students. 


\section{RESULTS AND DISCUSSION}

The first part of the practice, the measurement of the real power furnished by the different levels of microwave oven, is really important because each manufacturer has a different power specifications and irradiation distribution inside the cavity. ${ }^{5}$ The hottest region was initially determined by irradiating a fax paper at level 10 (maximum) for $60 \mathrm{~s}$. The darker region on the paper indicated the point where the greatest irradiation of the microwaves occurred, it was observed at the edges of the paper (Figure 2). The temperature increase of a certain mass of water is directly proportional to the incidence of microwave irradiation and, through the variation of temperature, one can calculate the power of the microwave oven in the different levels according to Equation 1.

$$
\mathrm{P}=(\text { Hc.n. } \Delta \mathrm{T}) / \mathrm{t}
$$

where: $\mathrm{P}=$ Power; $\mathrm{Hc}=$ Heat capacity of water $\left(75,312 \mathrm{~J} \cdot \mathrm{K}^{-1} \cdot \mathrm{mol}^{-1}\right)$; $\mathrm{n}=$ Number of mols of water; $\Delta \mathrm{T}=$ Temperature variation; $\mathrm{t}=$ Time $(\mathrm{s})$
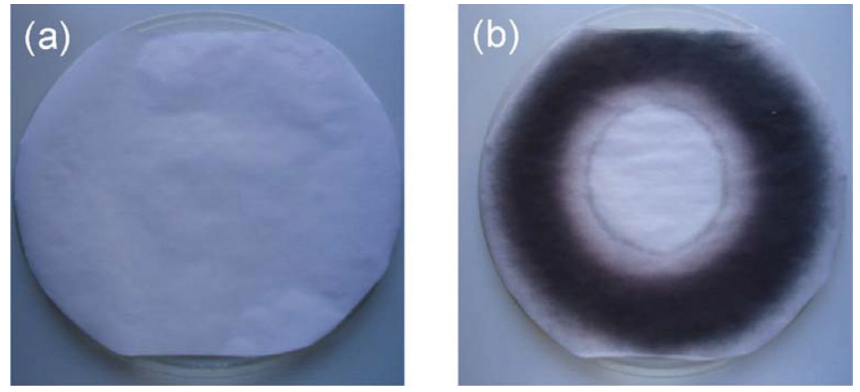

Figure 2. (a) Thermo sensitive fax paper before irradiation; (b) Thermo sensitive fax paper after irradiation, the dark region indicates higher incident radiation

To explore the real microwave effect and to find the best reactional conditions, we planned all the tests positioning the flask at the edge of the plate. As result, a total of $30 \mathrm{sec}$ irradiation divided in three pulses of $10 \mathrm{sec}$ was the best condition (Table 2S). This division in three heat steps is important to avoid an overheating of the reactional medium with concomitant product degradation and accidents.

The synthesis of umbelliferone (2) (Scheme 1) is performed via Pechmann condensation, a simple and widespread method to obtain coumarins. ${ }^{18,19}$ This reaction occurs in two mechanistic steps: (i) malic acid (3) generates the formyl acetic acid (4), in situ, which will act as electrophile of the reaction. Additionally to the production of formic acid, $\mathrm{CO}$ and water are generated in the acid medium. (ii) Formyl acetic acid (4) suffers a nucleophilic attack from resorcinol (5) to afford umbelliferone (2) as product. The synthesis completion was monitored by TLC.

The optimized protocol synthesis of umbelliferone (2) using domestic microwave oven demonstrated good yields, absence of organic solvents and abruptly decrease in reaction time in comparison to traditional protocol described in literature (Table 1). ${ }^{16}$

As known, hydroxy-coumarins might act as $\mathrm{pH}$ indicator. Thus we determined the $\mathrm{pKa}$ of compound 1 by means of spectrophotometric titration. It was observed that an increase in $\mathrm{pH}$ led to a slight
Table 1. Comparison of MAOS to traditional synthetic route to obtain umbelliferone (2)

\begin{tabular}{ccc}
\hline Metric & MAOS $^{a}$ & Traditional $^{b}$ \\
\hline Time & $30 \mathrm{sec}$ & $3-4 \mathrm{~h}$ \\
Solvent & None & $\mathrm{H}_{2} \mathrm{SO}_{4} /$ Ethanol \\
Yield & $77-92 \%$ & $71-82 \%$ \\
\hline
\end{tabular}

${ }^{a}$ Synthetic procedure using microwave protocol, malic acid, resorcinol and acid as reagents; ${ }^{19}{ }^{\text {b}}$ Conventional heating. ${ }^{16}$

hypochromic effect in the band centered at $320 \mathrm{~nm}$ while a new band arises at $365 \mathrm{~nm}$ forming an isosbestic point at approximately $336 \mathrm{~nm}$. This behavior is associated to the stabilization of $\pi \rightarrow \pi^{*}$ transition, since the deprotonation of 7-hydroxyl-coumarins increase the conjugation of the system.

The pKa value obtained for umbelliferone (2) in our laboratory class, using the Henderson Hasselback equation (2), was 7.6, quite similar to the value described in the literature $7.7 .{ }^{20}$ The $\mathrm{pKa}$ determination allows the students to understand this concept and also are very stimulating due to intense brightness of umbelliferone (2) observed under a $365 \mathrm{~nm}$ lamp, before and mainly after base addition (Figure 3).

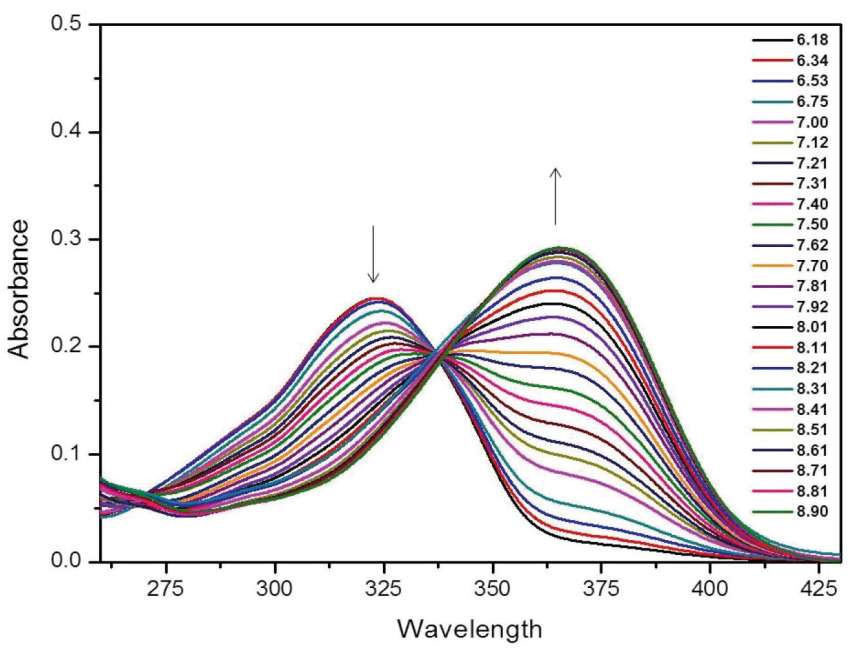

Figure 3. UV-vis spectra of umbelliferone (2) in Tris-HCl and after successive additions of Tris base

To determine the $\mathrm{pKa}$ value, a graph of $\log \left(\left(\mathrm{A}-\mathrm{A}_{\mathrm{f}}\right) /\left(\mathrm{A}_{0}-\mathrm{A}\right)\right)$ versus $\mathrm{pH}$ is plotted. The $\mathrm{pKa}$ is determined by the point of intersection of the y-axis ( $\mathrm{pH}$-axis), i.e. by the linear coefficient of the straight equation obtained (Figure 4).

\section{CONCLUSION}

All this practical class takes place over two laboratory classes and as such is suitable for second and third year undergraduate lab. The experiment shows important concepts in organic chemistry and analytical techniques. As discussed, the synthetic methodology approach as an eco-friendly alternative to traditional synthetic

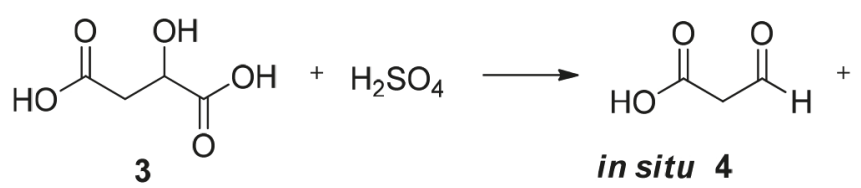<smiles>O=c1ccc2ccc(O)cc2o1</smiles>

Scheme 1. Synthesis of umbelliferone through formation of formyl acetic acid in situ 


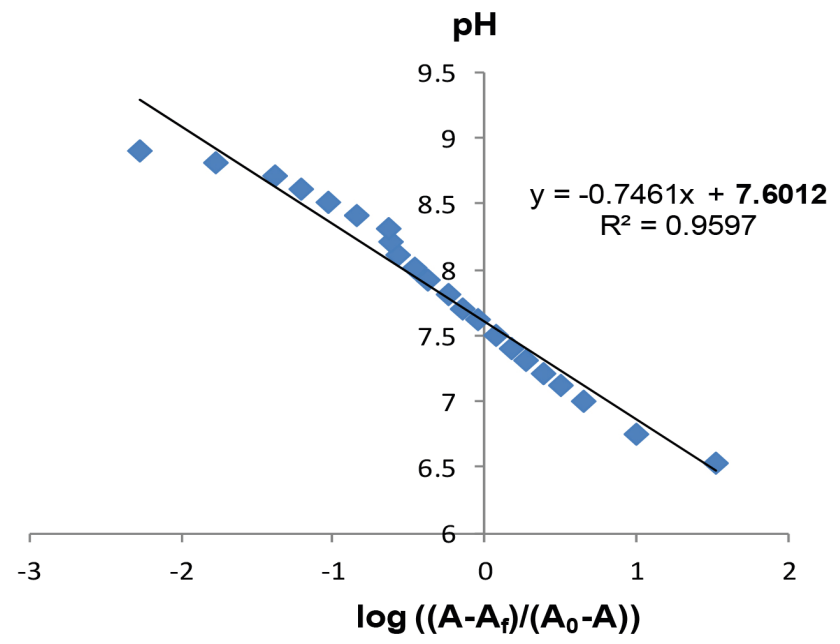

Figure 4. Graph of $p H$ versus $\log \left((A-A f) /\left(A_{0}-A\right)\right)$ at $323 \mathrm{~nm}$

methods for undergraduate students has demonstrated efficiency with good yields, being accessible due to their easy to execute and low cost. This experiment allows discussion of several interdisciplinary topics in chemistry, such as green chemistry, natural products, Pechmann condensation, microwave synthesis, UV-vis, TLC and fluorescence. Finally, this laboratory experiment can engage all students and is commonly recognized as the preferred practice class due to use of domestic microwave allied to the fluorescence observed which will help students in their understanding of how the mechanism of deprotonation of 7-OH-coumarins occurs.

\section{EXPERIMENTAL OVERVIEW}

\section{Microwave parameters adjustment}

The determination of the ideal domestic microwave parameters was divided in two steps. The first one was consisted in determining the region with higher radiation incidence using a thermo sensitive fax paper. In a simple experiment, the thermo sensitive fax paper was fixed over the microwave plate and irradiated for 5 seconds at the maximum power level (Figure 2). The second step was the determination of the real output power furnished by each microwave level step: a beaker with $500 \mathrm{~mL}$ of water was positioned at the edge of microwave plate (higher microwave incidence) and irradiated according to the possible domestic microwave power levels (Level $1,2,3,6,8$ and 10). In both cases the initial and final temperature of the water were measured and the experimental power values calculated by the equation (1). Results and more details are described in supporting information.

\section{Synthesis of umbelliferone (2)}

The synthetic procedure for obtaining umbelliferone (2) was carried out in only two steps (Scheme 2). The resorcinol (5) (20 mmol), malic acid (3) (20 mmol) and concentrated sulfuric acid $(100 \mathrm{mmol})$ were added in an Erlenmeyer flask $(50 \mathrm{~mL})$ and a glass funnel was adapted output of the flask. After adjusting the ideal reaction conditions of the domestic microwave oven (Table 2S), the Erlenmeyer with the reaction mixture was positioned at the edge of the microwave plate and irradiated for 30 seconds (Level 6) and then hot water was added $2-10 \mathrm{~mL}$ to the slurry. The mixture was cooled to room temperature, followed by crushed ice addition to give a precipitate which was filtered off and dried to afford the correspondent compound. The yield ranged from 52-77\% depending on the amount of water added. The structural elucidation was obtained using ${ }^{1} \mathrm{H}$ NMR and ${ }^{13} \mathrm{C}$ NMR spectroscopy.

\section{The pKa determination}

The pKa determination was evaluated by successive additions of Tris base over umbelliferone (2) dissolved in Tris- $\mathrm{HCl}$ solution. Briefly, $0.1 \mathrm{~mol}$ of Tris (1.2 g) was dissolved in $100 \mathrm{ml}$ of water and the $\mathrm{pH}$ was adjusted to 6.1 with $\mathrm{HCl}$. A non-quantitative amount of umbelliferone (2) was solubilized in Tris- $\mathrm{HCl}(\mathrm{pH}$ 6.18). The solution was filtered using a Millipore membrane filter apparatus and the UV-vis spectra was measured after successive additions of Tris base. Initially, the UV-vis spectra of umbelliferone (2) demonstrated an absorption band at $320 \mathrm{~nm}$. After successive additions of Tris base, a new absorption band arises at $365 \mathrm{~nm}$ corresponding to the deprotonated specie of umbelliferone (2) and a defined isosbestic point at $336 \mathrm{~nm}$ was observed. To calculate the $\mathrm{pKa}$ value we used de Henderson-Hasselback equation (Equation 2) where the absorption of the species in different $\mathrm{pH}$ was considered. A graph of $\mathrm{pH}$ versus $\log \left((\mathrm{A}-\mathrm{Af}) /\left(\mathrm{A}_{0}-\mathrm{A}\right)\right)$ was plotted and the $\mathrm{pKa}$ value of umbelliferone (2) was determined as 7.6.

$$
p H=p K a+\log \frac{\left[A^{-}\right]}{[H A]}
$$

where: $\left[\mathrm{A}^{-}\right]=$Concentration of deprotonated species; $\left[\mathrm{HA}^{-}\right]=$ Concetration of protonated species.

The Equation 2 can be expressed in terms of absorbance like Equation 3:

$$
p H=p K a+\log \frac{\left(A-A_{f}\right)}{\left(A_{0}-A\right)}
$$

where: $A=$ absorption of the mixture; $A_{f}=$ final absorption; $A_{i}=$ initial absorption.

The final absorption band is correspondent to the deprotonated umbelliferone (2) specie whereas the initial one is correspondent to the protonated molecule.

\section{Fluorescence}

To introduce to the students the concepts of fluorescence technique, a fluorescence spectrum of umbelliferone (2) was obtained. A non-quantitative amount of umbelliferone (2) was dissolved in water $(\mathrm{pH}=6.0)$. The solution was filtered with using a Millipore membrane filter apparatus and the fluorescence spectra was measured irradiating at $320 \mathrm{~nm}$. Umbelliferone (2) has shown a maximum emission band at $450 \mathrm{~nm}$ (blue region) (Figure 8S).<smiles>O=C(O)CC(O)C(=O)O</smiles><smiles>Oc1cccc(O)c1</smiles>

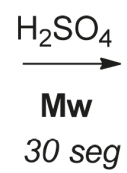<smiles>O=c1ccc2ccc(O)cc2o1</smiles>

Scheme 2. Synthetic procedure for obtaining umbelliferone (2) 


\section{Hazards}

All students must use glasses, lab coats and gloves. The experiment should be done in a well ventilated laboratory because release of gas occurs which can cause eye, skin and respiration irritation. All preparation and reaction are carried out under fume hood conditions, in which the risk of exposure is minimal. Resorcinol can be damage with chronic exposure, absorbed through open wound or ingested. Sulfuric acid should be handled with care because it is a corrosive liquid that can cause severe burns and malic acid in excessive contact with the skin can cause irritation.

\section{Lesson Planning}

The practical class was designed to be taken by second and third year undergraduate chemistry students at Rural Federal University of Rio de Janeiro (UFRRJ). During the class, the students worked in pairs to synthesize the umbelliferone (2) and determine its pKa value after successive titrations with basic solution. The chemistry practical class was divided into two parts needing two days to be completed (day one: synthesize the umbelliferone; day two: determined its $\mathrm{pKa}$ value), during sessions of $4 \mathrm{~h}$ and $3 \mathrm{~h}$, respectively.

Before the practice, all students need to read a text and answer some questions about the theme (supporting information), these questions allow the students to learn about the topics as Pechmann condensation, microwave synthesis, pKa definition, UV-vis, fluorescence and ${ }^{1} \mathrm{H}$ NMR spectroscopy.

The instructor should emphasize that the microwave synthesis is greener than traditional chemistry, ${ }^{21}$ demonstrating the reduction of time reaction, the possible absence of solvent and the higher yields. This concept can be easy understood comparing the results obtained during the laboratory practical with the traditional methodology previous described in literature (Table 1). ${ }^{16}$ The standard protocol using conventional heating to synthesize umbelliferone (2) can be performed by a laboratory assistant or just presented to students (Table 1).

Finally, it is very interesting to the instructor presenting the fluorescent characteristics of umbelliferone (2), using an apparatus containing a long wave UV lamp (365 nm) and a dark box. Furthermore, it is possible to introduce the pKa principle showing how the fluorescence is $\mathrm{pH}$ dependent due to the deprotonation of the hydroxyl group.

\section{SUPPLEMENTARY MATERIAL}

The Supporting Information is available on http:/quimicanova. sbq.org.br. Instructions for students, safety information, ${ }^{1} \mathrm{H}$ NMR and ${ }^{13} \mathrm{C}$ NMR spectra of umbelliferone (2), UV-Vis spectroscopy assay and note for instructors.

\section{ACKNOWLEDGMENTS}

This work was supported by Fundação de Amparo à Pesquisa do Estado do Rio de Janeiro (FAPERJ), Conselho Nacional de Desenvolvimento Científico e Tecnológico (CNPq) and Coordenação de Aperfeiçoamento de Pessoal de Nível Superior (CAPES).

\section{REFERENCES}

1. Russell, C. B.; Mason, J. D.; Bean, T. G.; Murphree, S. S.; J. Chem. Educ. 2014, 91, 511.

2. Andrade, P.; Galo, O. A.; Carvalho, M. R.; Lopes, C. D.; Carneiro, Z. A.; Costa, R. S.; Melo, E. B.; Silva, J. S.; Carvalho I.; Bioorg. Med. Chem. 2015, 23, 6815.

3. Kappe, C. O.; Dallinger, D.; Nat. Rev. Drug Discov. 2006, 5, 51.

4. Barboza, A. C. R. N.; Cruz, C. V. M. S.; Graziani, M. B.; Lorenzetti, M. C. F.; Sabadini, E; Quim. Nova 2001, 24, 901.

5. Crouch, R. D.; Howard, J. L.; Zile, J. L.; Barker, K. H.; J. Chem. Educ. 2006, $83,1658$.

6. Lidstrom, P.; Tierney, J.; Wathey, B.; Westman, J.; Tetrahedron 2001, 57, 9225; Cunha, S.; Santos Filho, R. F.; Riatto, V. B.; Dourado, G. A. A.; Quim. Nova 2013, 36, 190; Konrath, E. L.; Piedade, M.; Eifler-Lima, V. L.; Quim. Nova 2012, 35, 1887; Teixeira, E. F.; Santos, A. P. B.; Bastos, R. S.; Pinto, A. C.; Kümmerle, A. E.; Coelho, R. R.; Quim. Nova 2010, 33, 1603.

7. Langa, F.; Cruz, P. D. L.; Hoz, A. D. L.; Ortiz, A. D.; Barra E. D.; Contemp. Org. Synth. 1997, 4, 373.

8. Gabriel, C.; Gabriel, S.; Grant, E. H.; Halstead, B. S. J.; Mingos, D. M. P.; Chem. Soc. Rev. 1998, 27, 213.

9. Pereira, T. M.; Vitório, F.; Amaral, R. C.; Zanoni, K. P. S.; Iha, N. Y. M.; Kummerle, A. E.; New J. Chem. 2016, 40, 8846.

10. Vitorio, F.; Pereira, T. M.; Castro, R. N.; Guedes, G. P.; Graebin, C. S.; Kummerle, A. E.; New J. Chem. 2015, 39, 2323.

11. Pereira, T. M.; Franco, D.; Vitorio, F.; Kümmerle, A. E.; Curr. Top. Med. Chem. 2018, 18, 124.

12. Azuma, K.; Suzuki, S.; Uchiyama, S.; Kajiro, T.; Santa, T.; Imai, K.; Photochem. Photobiol. Sci. 2003, 2, 443.

13. Du, L.; Li, M.; Zheng, S.; Wang, B.; Tetrahedron Lett. 2008, 49, 3045.

14. Fink, D. W.; Koehler, W. R.; Anal. Chem. 1970, 42, 990.

15. Sánchez, C. G.; Casilda, V. C.; Mayoral, E. P.; Aranda, R. M. M.; Peinado, A. J. L.; Bejblová, M.; Cejka, J.; Catal. Lett. 2009, 128, 318.

16. Xie, S. S.; Wang, X. B.; Li, J. Y.; Yang, L.; Kong, L. Y.; Eur. J. Med. Chem. 2013, 64, 540.

17. Bulut, M.; Erk, C.; Dyes Pigm. 1996, 30, 99.

18. Helavi, V. B.; Solabannavar, S. B.; Salunkhe, R. S.; Mane, R. B.; J. Chem. Res. 2003, 279.

19. Symeonidis, T.; Chamilos, M.; Litina, D. J. H.; Kallitsakis, M.; Litinas, K. E.; Bioorg. Med. Chem. Lett. 2009, 19, 1139.

20. Krylov, S. N.; Dunford, H. B.; J. Phys Chem. 1996, 100, 19719.

21. Montes, I.; Sanabria, D.; García, M.; Castro, J.; Fajardo, J.; J. Chem. Educ. 2006, 83, 628. 